\title{
AN INVENTORY OF CREATIVE SPACES: INNOVATIVE ORGANIZATIONS AND THEIR WORKSPACE
}

\author{
Thoring, Katja (1,2); Mueller, Roland M. (3); Badke-Schaub, Petra (1); Desmet, Pieter (1) \\ 1: TU Delft, The Netherlands; 2: Anhalt University of Applied Sciences, Germany; 3: Berlin School of \\ Economics and Law, Germany
}

\begin{abstract}
Creative workspaces are becoming popular in many organizations. They are believed to support innovation efforts and creativity among employees. This paper presents spatial evidences of creative work environments from real-life organizations, based on an exploratory multi-case study in 18 institutions. The found workspaces were mapped and categorized according to the qualities they might provide for affecting creativity. The resulting inventory of creative spaces contributes to the emerging interest on creative workspace design by presenting inspiring best-practice examples. The shown examples provide the readers with a better understanding how a creative space could be designed in order to provide an environment for an innovative organisation. Related literature was added to explain the possible impact of specific spatial configurations.
\end{abstract}

Keywords: Workspaces for design, Innovation, Design management, Case study, Design practice

\section{Contact:}

Thoring, Katja

TU Delft

Industrial Design Engineering

The Netherlands

k.c.thoring@tudelft.nl

Cite this article: Thoring, K., Mueller, R.M., Badke-Schaub, P., Desmet, P. (2019) 'An Inventory of Creative Spaces: Innovative Organizations and their Workspace', in Proceedings of the 22nd International Conference on Engineering Design (ICED19), Delft, The Netherlands, 5-8 August 2019. DOI:10.1017/dsi.2019.7 


\section{INTRODUCTION}

The term 'creative space' describes a relatively recent phenomenon of innovative workplace design. The general understanding of a creative workspace is largely influenced by companies, such as Google, who were among the first to implement fancy open-plan office spaces with unusual furniture (Figure 1). This image can lead to the premature assumption that one only needs to install such peculiar interior elements to automatically transform the organisation into a successful innovation game changer. Unfortunately, it is not that simple. The system of creative space is far more complex and involves more aspects and parameters than just 'different' interior designs. Hence, a better understanding of the qualities of creative spaces and their possible impact on the organization and its employees is crucial.

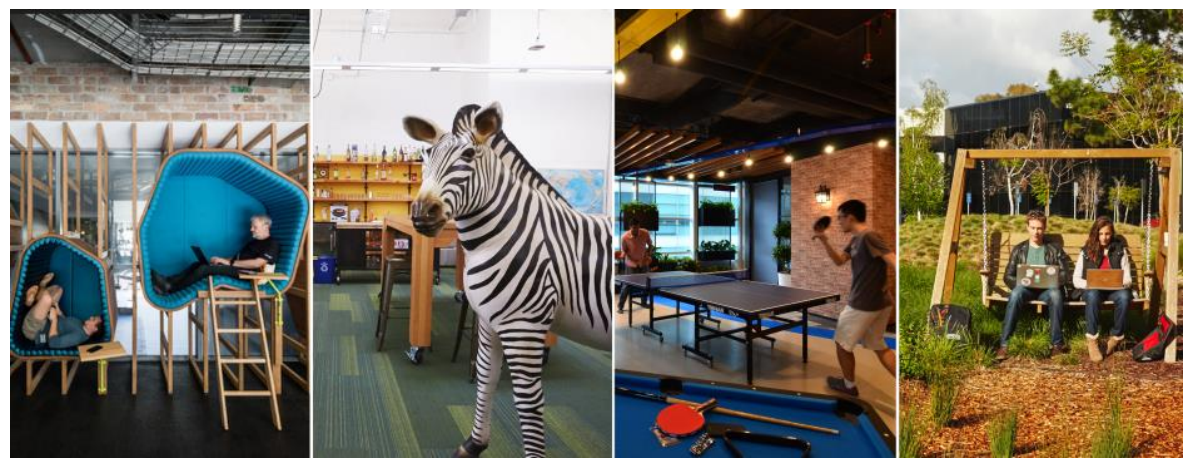

Figure 1. Google office and campus workspaces; privacy pods, playful zebra statue, table tennis, and outdoor swing for recreation (photos: Google, with permission)

We define creative spaces as physical structures and elements at different scales that are deliberately designed to support creative work processes or to facilitate creativity. The scales of the physical structures and elements can vary from individual items, such as pieces of furniture, to the room's layout and interior design, and from the architectural building to the location within a specific civic neighbourhood (Thoring et al., 2018a). It covers spaces in both educational and corporate environments, as well as special forms such as co-working spaces or innovation labs.

Following this definition, a creative space does not necessarily look different than a traditional office space, as long as it is able to facilitate creative activities. Organizations who want to implement creative spaces and seek for information and inspiration on the topic can select between various coffee table books and a newly emerging body of scientific research on the topic. However, the available scientific studies are usually theoretical without tangible examples, or they focus on single cases, whereas the various available coffee-table books on creative spaces do not provide any scientific underpinning that would tell the readers which spatial design would be suitable for what purpose and effect. Publications that provide examples of diverse creative workspaces from various organizations of different sizes, along with related scientific underpinning, are rare. This paper tries to fill this gap. We present an exploratory case study of 18 creative spaces from small and medium-sized companies, as well as from design educational institutions. In order to systematically analyse the 18 spaces, we refer to an empirically developed typology of creative spaces by Thoring et al. (2018a) that distinguished between five types and five qualities of a creative space (Figure 2).
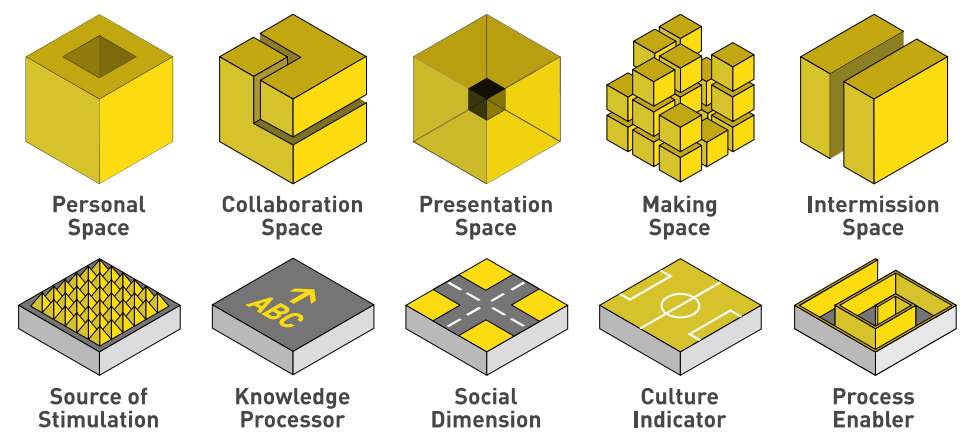

Figure 2. Space types (top) and qualities (bottom) of a creative space (Thoring et al., 2018a) 
According to this typology, there exist five different types of creative spaces that are dedicated to different creative activities: (1) personal space, (2) collaboration space, (3) making space, (4) presentation space, and (5) intermission space (Figure 2). Moreover, a creative space can provide several qualities: (1) it can be a source of stimulation, (2) it can act as a knowledge processor, (3) it can represent or influence the organizational culture, (4) it can facilitate social interaction, and (5) it can enable specific workflows and processes (Figure 2). This paper presents spatial evidences of creative work environments from real-life organizations and maps them to the spatial qualities, as mentioned above. Such examples of creative workspace designs provide the readers with a better understanding how a creative space could be designed in order to provide an environment for an innovative organisation. As outlined by Thoring et al. (2018a), the qualities of a space to provide adequate stimulation, to facilitate knowledge processing, to adhere to an innovation culture, to instigate social interaction, and to enable process workflows, are critical for a successful creative work environment. Consequently, this paper tries to answer the following research question:

\section{$R Q:$ What examples of creative spaces can be found in real-life organisations that provide specific spatial qualities for enabling creative activities?}

In the following sections, we present related work on creative workspaces (Section 2), describe our methodological approach for analysing the work environments of 18 selected organizations (Section 3), and present exemplary creative spaces according to the five categories of spatial quality enhancement along with references to related literature (Section 4). We conclude by discussing the results, implications, and limitations (Section 5).

\section{RELATED WORK}

There exists a large number of 'coffee table books' on the topic of creative space in office environments (e.g. Borges et al., 2013; Georgi and McNamara, 2016; Grieco and Rossum-Willems, 2017; GrovesKnight and Marlow, 2016; Stewart, 2004), and also in educational contexts (e.g. Dudek, 2012; Ehmann et al., 2012; Mirchandani, 2015). Interested readers can consult theses sources to find inspirational examples of creative workspace designs. However, these books rarely provide any theoretical background and explanations about the possible impact of the spatial designs. Only recently has scientific research on the possible impact of creative spaces on innovation processes emerged. For example, several authors presented case studies of creative work environments (Kristensen, 2004; Lindahl, 2004; Lewis and Moultrie, 2005; Magadley and Birdi, 2009; Thoring et al., 2018b). Others use questionnaires or surveys, along with photographs of creative spaces, to empirically investigate people's self-assessment of their work environments (Bryant, 2012; Ceylan et al., 2008; Dul and Ceylan, 2011; Lin, 2009; McCoy and Evans, 2005; Paoli et al., 2017; Paoli and Ropo, 2017). Several authors have developed theories about the possible influence of space on creativity, mainly based on expert interviews (Dul et al., 2011; Groves-Knight and Marlow, 2016; Martens, 2011; Oksanen and Ståhle, 2013; Thoring et al., 2017a). Some authors presented tools or guidelines for developing creative spaces (Doorley and Witthoft, 2012; Snead and Wycoff, 1999; Thoring et al., 2017b, 2016). Only a few authors presented experimental studies to investigate actual effects of spatial modifications (e.g. McCoy and Evans, 2002; Magadley and Birdi, 2009; Kangas, 2010; Waber et al., 2014).

\section{METHODOLOGY}

In order to learn more about possible characteristics of creative spaces, we conducted a multi-case study in 18 organisations in which we looked for real-life examples of creative work environments. We followed the case study method suggested by Yin and conducted an exploratory, holistic multi-case study (Yin, 2003, p. 39). According to our research question, we searched for spatial characteristics that could be mapped to a particular spatial quality (cultural impact, social interaction, stimulation, knowledge processing, or process enabling, as suggested by Thoring et al. (2018a)). In an inductive approach, we searched for peculiar spatial instantiations, from which we inferred conceptual connections to these spatial qualities. These institutions were selected to cover creative work environments in various countries, including Germany, the Netherlands, the United Kingdom, Portugal, Sweden, the United States, and China. The different national origins were chosen to rule out the possibility of culturespecific peculiarities, but not to compare cultural differences between countries. Therefore, a strict representation of national cultures in equal numbers appeared not necessary. The included institutions 
should have a somewhat 'creative' focus, which could be (1) a creative educational program such as art, design, or architecture, (2) a small or globally operating design firm, (3) an innovation department of a large global corporation, or (4) a coworking space or makerspace. The selected 18 institutions represent different corner cases and hence illuminate the topic of interest from different perspectives (Table 1).

Table 1. Overview of the 18 included organizations
Institution
Code Origin
Description
PRA EDU

\begin{tabular}{|c|c|c|c|c|c|c|}
\hline 1 & $\begin{array}{l}\text { Umeå School of } \\
\text { Architecture }\end{array}$ & EDU-1 & $\begin{array}{l}\text { Northern } \\
\text { Europe (SE) }\end{array}$ & $\begin{array}{l}\text { Design/Architecture faculty } \\
\text { (small size) }\end{array}$ & & $\mathrm{x}$ \\
\hline 2 & $\begin{array}{l}\text { Technical University } \\
\text { Delft }\end{array}$ & EDU-2 & $\begin{array}{l}\text { Central Europe } \\
(\mathrm{NL})\end{array}$ & $\begin{array}{l}\text { Faculty of Industrial Design } \\
\text { (large size) }\end{array}$ & & $\mathrm{x}$ \\
\hline 3 & ESAD, Porto & EDU-3 & $\begin{array}{l}\text { Southern } \\
\text { Europe (PT) }\end{array}$ & $\begin{array}{l}\text { ESAD College of Art \& Design } \\
\text { (small size) }\end{array}$ & & $\mathrm{x}$ \\
\hline 4 & $\begin{array}{l}\text { Central Saint Martins } \\
\text { College }\end{array}$ & EDU-4 & $\begin{array}{l}\text { Northern } \\
\text { Europe (UK) }\end{array}$ & $\begin{array}{l}\text { Art \& Design School } \\
\text { (large size) }\end{array}$ & & $\mathrm{x}$ \\
\hline 5 & PolyU Hong Kong & EDU-5 & Asia $(\mathrm{CN})$ & $\begin{array}{l}\text { Innovation Tower, } \\
\text { Design faculty (medium size) }\end{array}$ & & $\mathrm{x}$ \\
\hline 6 & $\begin{array}{l}\text { School of the Art } \\
\text { Institute of Chicago }\end{array}$ & EDU-6 & $\begin{array}{l}\text { Northern } \\
\text { America (US) }\end{array}$ & $\begin{array}{l}\text { Art \& Design School, Chicago } \\
\text { (large size) }\end{array}$ & & $\mathrm{x}$ \\
\hline 7 & $\begin{array}{l}\text { Parsons School of } \\
\text { Design }\end{array}$ & EDU-7 & $\begin{array}{l}\text { Northern } \\
\text { America (US) }\end{array}$ & $\begin{array}{l}\text { Art \& Design School, New York } \\
\text { (large size) }\end{array}$ & & $\mathrm{x}$ \\
\hline 8 & $\begin{array}{l}\text { Design Academy, } \\
\text { Berlin }\end{array}$ & EDU-8 & $\begin{array}{l}\text { Central Europe } \\
\text { (DE) }\end{array}$ & $\begin{array}{l}\text { Private Design School } \\
\text { (small size) }\end{array}$ & & $\mathrm{x}$ \\
\hline 9 & $\begin{array}{l}\text { Detmold School of } \\
\text { Architecture }\end{array}$ & EDU-9 & $\begin{array}{l}\text { Central Europe } \\
\text { (DE) }\end{array}$ & $\begin{array}{l}\text { Architecture School } \\
\text { (medium size) }\end{array}$ & & $\mathrm{x}$ \\
\hline 10 & $\begin{array}{l}\text { School of Design } \\
\text { Thinking }\end{array}$ & EDU-10 & $\begin{array}{l}\text { Central Europe } \\
\text { (DE) }\end{array}$ & $\begin{array}{l}\text { Design Thinking further } \\
\text { education and professional } \\
\text { training (small size) }\end{array}$ & (x) & $\mathrm{x}$ \\
\hline 11 & IDEO & PRA-1 & $\begin{array}{l}\text { Northern } \\
\text { America (US) }\end{array}$ & $\begin{array}{l}\text { Global design consultancy, } \\
\text { Munich branch }\end{array}$ & $\mathrm{x}$ & \\
\hline 12 & $\begin{array}{l}\text { Steelcase Learning } \\
\text { and Innovation Center }\end{array}$ & PRA-2 & $\begin{array}{l}\text { Northern } \\
\text { America (US) }\end{array}$ & $\begin{array}{l}\text { Furniture Manufacturer, } \\
\text { Innovation Center, Munich } \\
\text { branch }\end{array}$ & $\mathrm{x}$ & \\
\hline 13 & $\begin{array}{l}\text { MHP Porsche Digital } \\
\text { Lab }\end{array}$ & PRA-3 & $\begin{array}{l}\text { Central Europe } \\
\text { (DE) }\end{array}$ & $\begin{array}{l}\text { Porsche car manufacturer, } \\
\text { digital innovation lab }\end{array}$ & $\mathrm{x}$ & \\
\hline 14 & $\begin{array}{l}\text { SAP, Innovation Lab, } \\
\text { AppHaus }\end{array}$ & PRA-4 & $\begin{array}{l}\text { Central Europe } \\
\text { (DE) }\end{array}$ & $\begin{array}{l}\text { Software company, headquarter, } \\
\text { Innovation Lab }\end{array}$ & $\mathrm{x}$ & \\
\hline 15 & Zoku & PRA-5 & $\begin{array}{l}\text { Central Europe } \\
(\mathrm{NL})\end{array}$ & Coworking Space & $\mathrm{x}$ & \\
\hline 16 & Launchlabs, Berlin & PRA-6 & $\begin{array}{l}\text { Central Europe } \\
\text { (DE) }\end{array}$ & Berlin-based Startup & $\mathrm{x}$ & \\
\hline 17 & UnternehmerTUM & PRA-7 & $\begin{array}{l}\text { Central Europe } \\
\text { (DE) }\end{array}$ & $\begin{array}{l}\text { Incubator of Technical } \\
\text { University Munich }\end{array}$ & $\mathrm{x}$ & $(\mathrm{x})$ \\
\hline 18 & $\begin{array}{l}\text { Design Lab University } \\
\text { of Twente }\end{array}$ & PRA-8 & $\begin{array}{l}\text { Central Europe } \\
(\mathrm{NL})\end{array}$ & Incubator of Twente University & $\mathrm{x}$ & (x) \\
\hline
\end{tabular}

We focused on direct observations and artefacts to identify peculiar spatial configurations. In each institution, two researchers were given a tour guided by a staff member. During the tour, we asked a set of open questions regarding (1) how the spaces were usually used and (2) why or why not those spaces were considered successful to facilitate creative activities. Each visited room and also the transition spaces like hallways were photographed and one researcher took notes of the guide's responses. After the official tour, the researchers were able to spend between several hours and several 
days independently in each organization, and hence were able to observe how the spaces were actually used by the users during their daily activities. The researchers took notes of their observations for later analysis. As a result, we collected a total of approximately 1000 photographs. After removing duplicates and redundant pictures (e.g. the same motif from various perspectives, or similar items in the same institution), approximately 300 pictures remained for our analysis. We organized the photographs in an Excel table that served as our case study database. Here, we added a description for each picture, as well as our field notes and insights from the guides' responses, and marked the observed scale, space type, and the addressed spatial quality. The diagram depicted in Figure 3 outlines a space's observed characteristics and the anticipated connection to creativity.

Each observed spatial instantiation is represented on a spatial scale and is used for a creative activity in a specific space type). This spatial configuration influences one or more spatial qualities.

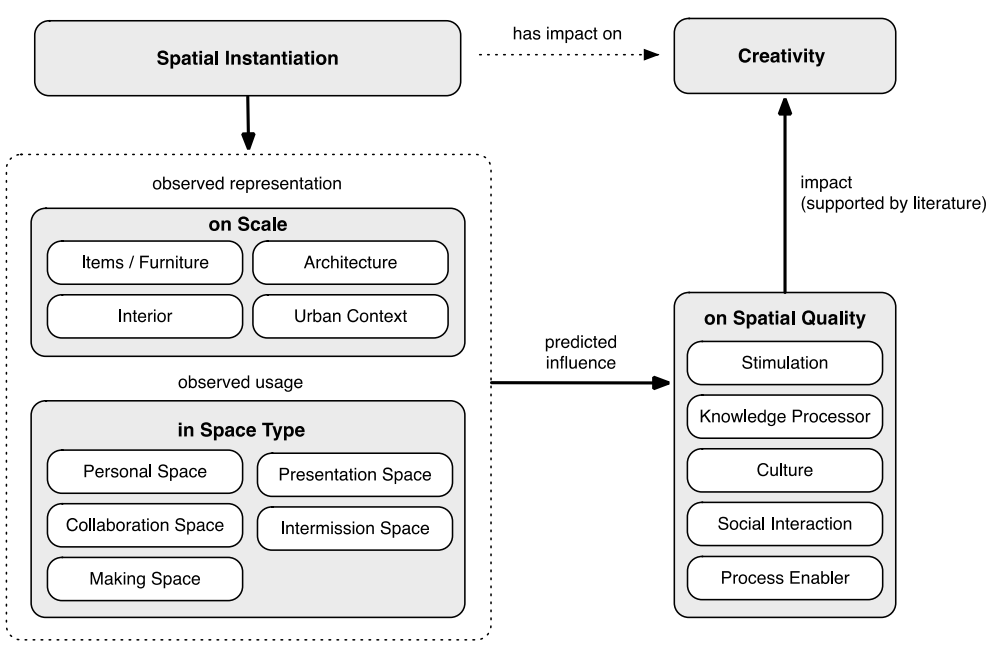

Figure 3. Relationship of spatial instantiations and possible impact.

According to this diagram, the spatial quality is the key factor for a space's capability to affect creativity and hence we clustered the photographs accordingly (see Section 4). The case study database allowed us to filter the data according to specific parameters (e.g., to cluster all found instantiations that would provide stimulation, etc.). Finally, we searched for related literature that would possibly provide explanations and a theoretical underpinning for the possible impact of the spatial quality on creativity.

\section{RESULTS}

\subsection{Creative space as a source of stimulation}

The design of a workspace can provide various sources of stimulation. For example, a loose arrangement of varied-sized windows can result in unexpected and varying views (Figure 4A). Also, the presence of artefacts, (e.g. work models or previous projects) can be a source of inspiration. Shelves to display such objects can be found in various institutions. Some examples were arranged in a way that visual transparency was kept in order to provide inspiring views into other rooms (Figure 4B, 4C). Furthermore, a good level of sound is important. The deliberate use of wooden lamellas reduces the noise level but allows visual contact to the workplace at the same time (Figure 4D). Plants were often used as visual stimulating room dividers (Figure 4E, 4F). Lounge areas to work in teams or individually with inspiring views might enhance ideation (Figure 4G). Tactile stimuli could be found in wall coverings, for example in a natural tree bark texture (Figure 4H). Blackboards often look uninspiring and messy, which could be turned into a visual attractive wall decoration by using graffiti backgrounds (Figure 4I).

According to Sarkar and Chakrabarti (2008), a stimulation is a 'trigger' that activates one or more senses and hence initiates the creative search and exploration process. Consequently, triggers can occur through visual, auditory, olfactory, tactile, or gustatory stimulation of the five senses (seeing, hearing, smelling, touching, or tasting). Such stimuli create a certain atmosphere in the workspace. Some stimuli, such as loud noises or unpleasant smells, can quickly become annoying or distracting. Others, such as visual textures or the smell of specific materials, might provide inspiration that 
facilitates creativity. A well-balanced composition of such stimuli is crucial to the constitution of a creative space.
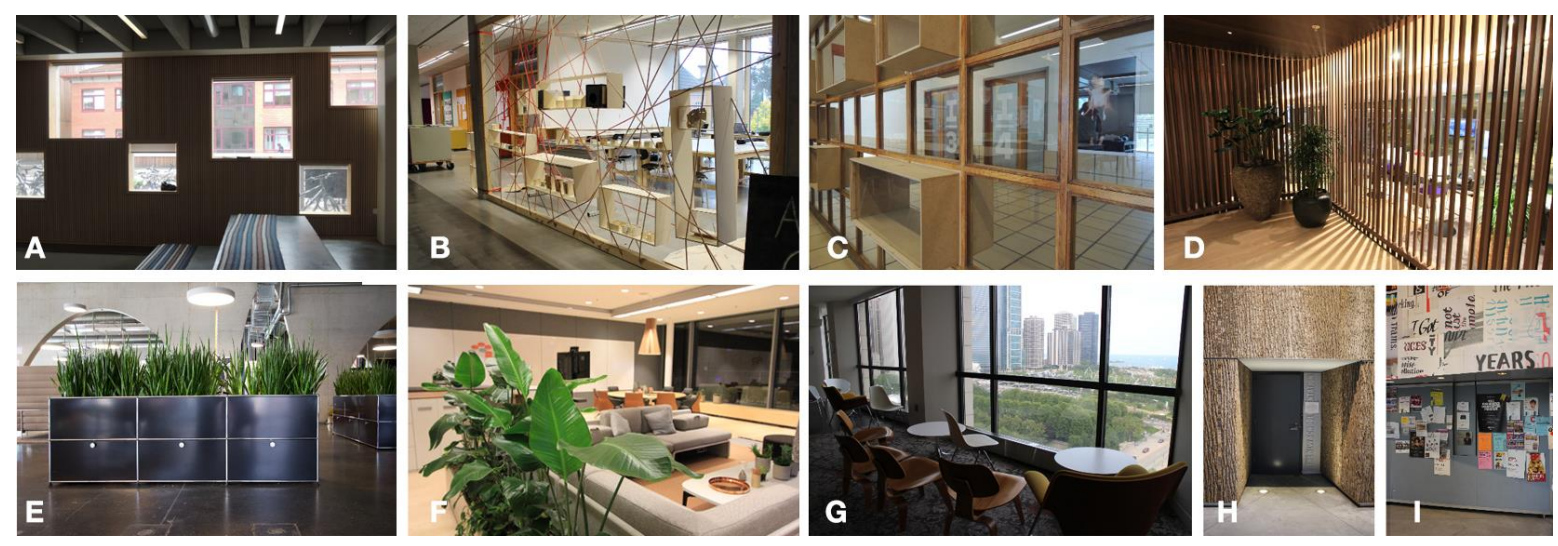

Figure 4. (A) Various window sizes and positions (EDU-1), (B), (C) transparent shelves (EDU-3, EDU-9), (D) wooden lamellas (PRA-2), (E), (F) plants for stimulation and as visual partitionment (PRA-2, PRA-3), (G) lounge area with a view (EDU-6), (H) tree bark wall covering (EDU-7), and (I) graffiti info board (EDU-7)

\subsection{Creative space as a knowledge processor}

The work environment can act as a knowledge processor by archiving and displaying information, data, and artefacts, and by facilitating exchange of information in written form, or verbally between people. Within the analysed institutions we found several instantiations of material libraries (e.g. Figure 5A, 5B). To capture ideas spontaneously, specific writeable furniture was present at several institutions (Figure 5C,5D) or in the form of writeable walls (Figure 5H). Furniture with printed guidelines or instructions for usage helped to communicate how to use tools or equipment (Figure 5E). Traditional book libraries were often integrated into lounge areas (Figure 5F) or accompanied by design or research guidelines (Figure 5I). Also, spaces for personal withdrawal were found, for example a secluded reading corner (Figure 5G). The exchange of tacit knowledge between people was often fostered through casual meeting areas (Figure 5H).
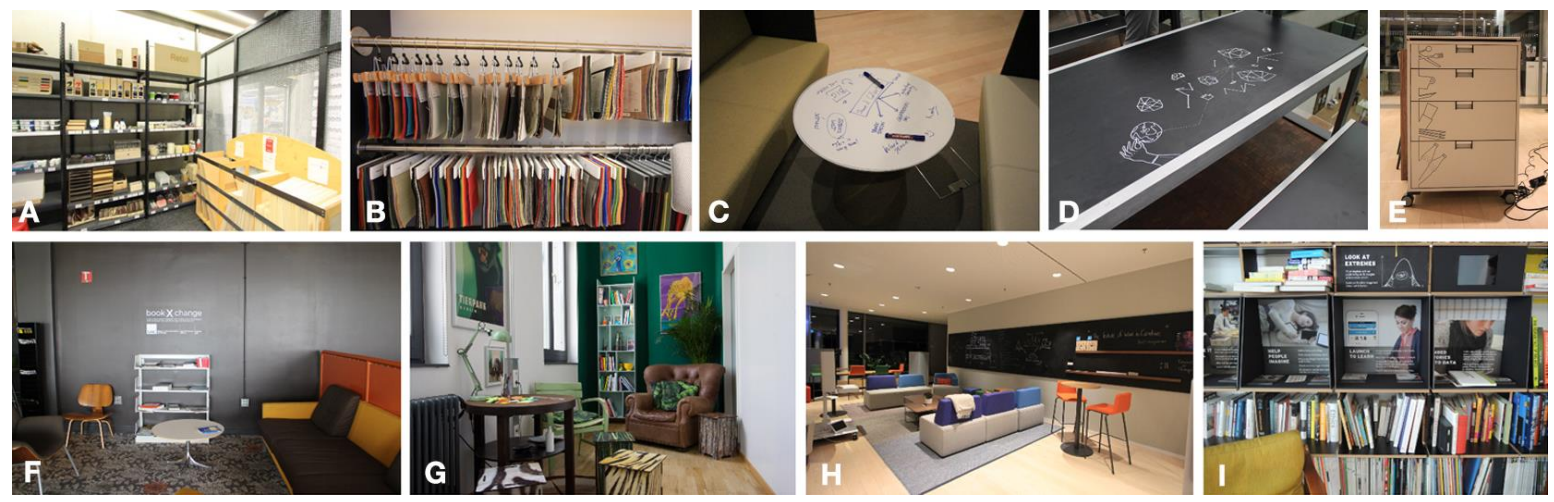

Figure 5. (A) material and tool library (PRA-7), (B) material and fabric library (PRA-2), (C) paper sheet table (PRA-2), (D) writable table (EDU-4), (E) storage unit with printed instructions (PRA-2), $(F)$ book exchange area (EDU-6), (G) casual reading corner (PRA-5), (H) socialization area with chalkboards

(PRA-2), (I) library with research instructions (PRA-1)

Cross (2001) points out that some knowledge is inherent in the design artefacts (e.g. in their forms and configurations). Materials, tools, or working models can provide access to such knowledge. Moreover, knowledge exchange and knowledge creation are particularly relevant for innovation processes. By recombining existing information and materials, new concepts might emerge. The space might facilitate this by displaying information and by inviting casual meetings and conversations to foster the exchange of tacit knowledge, which is inherent within people (Polanyi, 1966). Peschl and Fundneider (2014) discussed the role of the physical work environment for knowledge creation and innovation. They suggested different dimensions of 'enabling spaces' including physical space, emotional space, social space, cognitive space, 
epistemological space, and technical/virtual space. Thoring and Mueller (2014) presented a framework of spatial knowledge management that suggested different interior design approaches for facilitating (1) an artefact-based 'embodiment' strategy (2) a 'socialisation' strategy, and (3) a 'codification' strategy for managing design knowledge.

\subsection{Creative space as an indicator of organizational culture}

Organizational culture is closely related to innovation and creativity. On the one hand, the implementation of innovative work spaces can be used to demonstrate an existing organizational culture, while on the other hand these environments might be able to actually impact people's behaviour, work performance, and also the organization's culture itself (Miller et al., 2014). Such phenomena can be explained by the psychological concept of priming; the activation of a specific - for example, creative-mind-set (Sassenberg et al., 2017). The question arises, how organizations can express or adjust their respective culture through their spatial environment, in order to become a more creative organization.

In the analysed institutions, we found several instances of spatial designs that might impact people's mind-set by adding labels to their rooms that would suggest a specific creative behaviour (Figure 6A). Other examples of visual signages illustrate work ethics or mission statements (Figure 6B). Some labels of rooms suggest a specific behaviour, such as meditating, praying, or simply quiet time (e.g. quiet capsule, Figure 6E). A portrait gallery (Figure 6D) might enhance the bonding and hence the loyalty to a company (Figure 6D). And finally, a rough and improvised furniture concept or branding might help to encourage experimentation and creative exploration (Figure 6F, 6H). Examples of succsuccess stories might enhance motivation (6G).
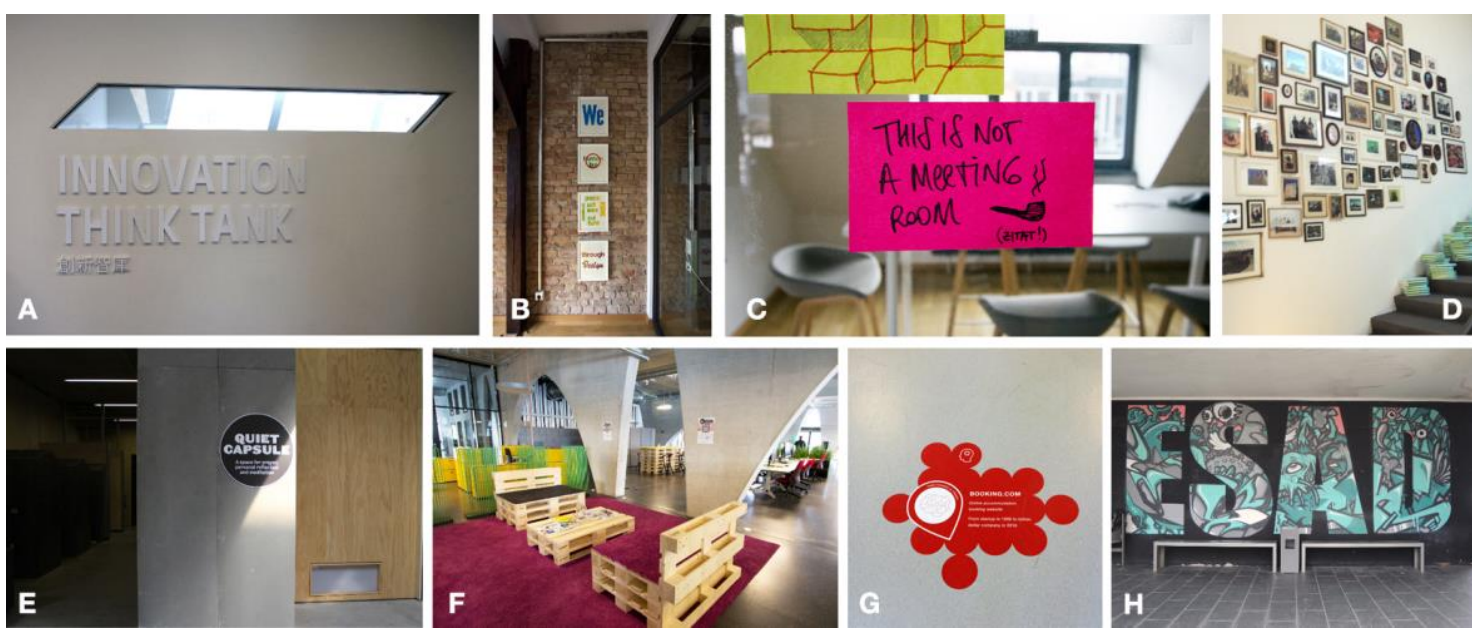

Figure 6. (A) room name for innovation (EDU-5), (B) visualized mission statement (PRA-5), (C) "This is not a meeting room" (PRA-5), (D) portrait gallery (PRA-1), (E) quiet capsule (EDU-4), (F) rough DIY furniture (PRA-3), (G) floor sticker presents successful startup (PRA-8), (H) graffiti-style logo (EDU-3)

\subsection{Social dimension of creative spaces}

Social interaction and collaboration are another aspect considered relevant for innovation. The workspace design can facilitate informal meetings, collaboration, and coincidental running into each other. Examples from our analysed cases include hallway workstations that enable team work and meetings with passers-by (Figure 7A). Cafeterias, coffee stations, and even a mobile food truck bring the staff together and enable informal communication (Figure 7B). Several of our analysed institutions make use of large staircases in their buildings, where people would meet several times throughout the day (Figure 7C). In several organizations we found high-back furniture that allows private discussions (Figure 7D) or 'quiet capsules' for personal withdrawal (7E). Some companies installed communal tables with additional silence-hoods to enable quiet 'alone'-work while being in company (Figure 7F). A communal kitchen for joint lunch breaks is present in many innovative companies (Figure 7G). Other found examples include secluded booths for small team meetings (Figure $7 \mathrm{H}$ ), and small wallmounted hallway tables, for spontaneous discussions on coincidental meetings (Figure 7I). 
Collaboration in teams as well as informal knowledge exchange are considered key for creative innovation efforts (Svihla, 2010). The layout of a creative space can enhance such social interactions (Snead and Wycoff, 1999) by, for example, providing collaboration furniture (Doorley and Witthoft, 2012) or by placing meeting points, such as coffee machines or copiers, in strategically central locations to instigate informal meetings. The studies reported by Waber et al. (2014) experimentally investigated the impact of spatial changes that would increase social interactions on the company's sales.
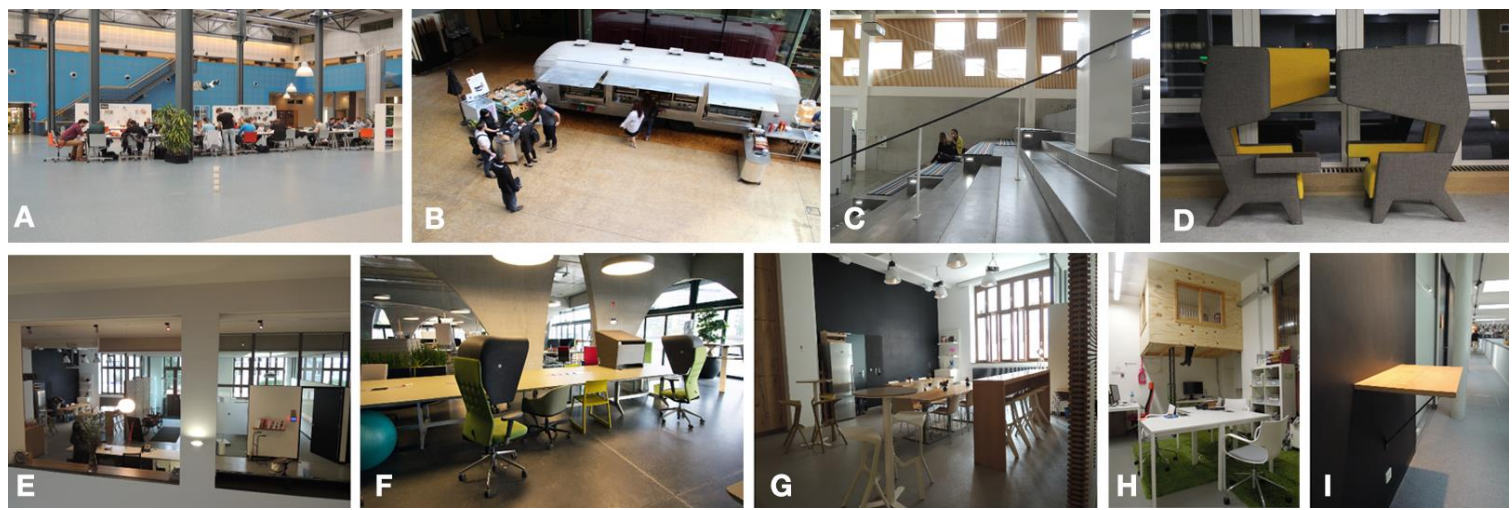

Figure 7. (A) hallway workstations (EDU-2), (B) food truck on-site (EDU-4), (C) hallway stairs as meeting spot (EDU-1), (D) consultation space for two (PRA-4), (E) vistas across rooms (PRA-1), $(F)$ communal table with acoustic pods (PRA-3), (G) kitchen area for social exchange (PRA-1), (H) elevated observation booth as meeting space (PRA-6), (I) wall-mounted tables in hallways (PRA-1)

\subsection{Creative space as a process enabler}

The configuration of furniture can facilitate (or hinder) a specific work process. Pair-programming workstations enable two people to simultaneously programme software code (Figure 8A). Flexible furniture solutions allow for different usage scenarios like switching between play-mode and team meeting (Figure 8B). A supply store on the premises enables easy creation of ideas and models (Figure 8C). Available tools have a similar effect (Figure 8D). Shielded work chairs enable deep work (Figure 8E). Many of the visited companies had differently furnished booths for different work activities (Figure 8F). Flexible furniture solutions enable using one space for different purposes (Figure 8G), and sockets in hallways allow working in such transition spaces (Figure $8 \mathrm{H}$ ).
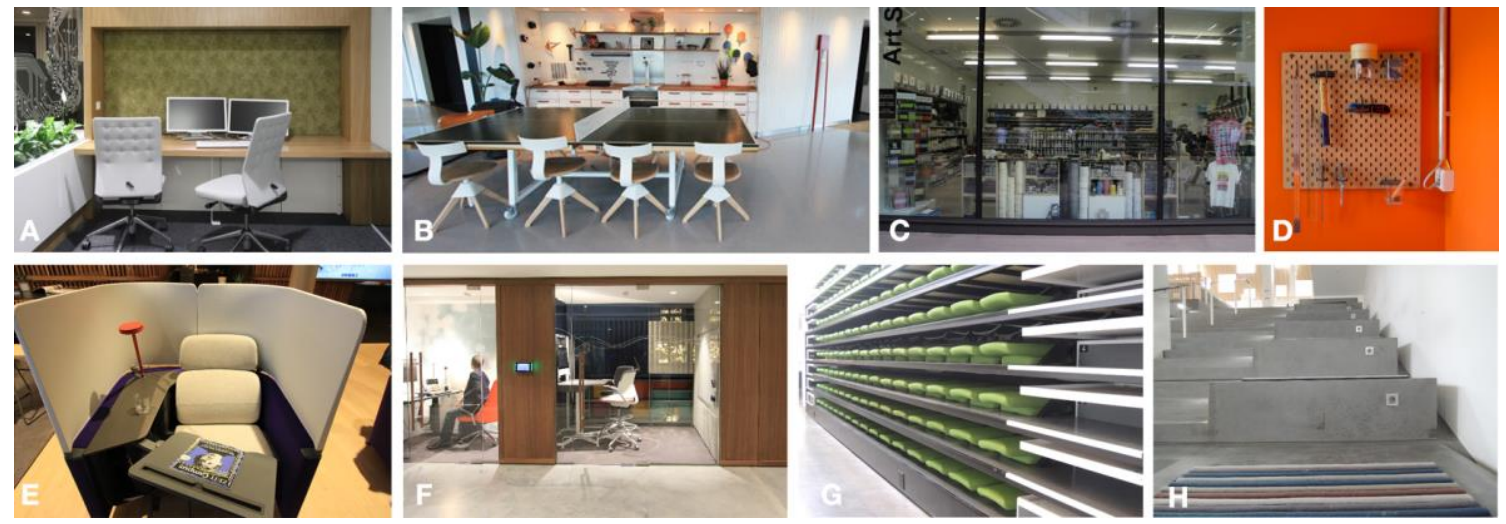

Figure 8. (A) pair programming (PRA-4), (B) Table tennis can be used for team meetings (PRA-5),

(C) supply store on-site (EDU-4), (D) prototyping tools in place (PRA-5), (E) secluded single workstation (PRA-2), (F) booths for different work modes (PRA-2), $(G)$ fold-away plenum seats (EDU-1), (H) sockets in hallways (EDU-1)

Workflow optimization has been studied extensively in various contexts. In the 20th century, research was focusing on optimizing industrial and, later, office workflows, which can be subsumed under the term 'Taylorism'. Later, the Japanese concept of Kaizen (Imai, 1986) refers to continuously 'improving' a business. The Toyota Production System (TPS) follows the Kaizen philosophy with the main goal to reduce waste in production processes (Kato and Smalley, 2012). For example, Toyota's mass assembly line workers have to stop their assembly line when a problem occurs, in order to solve it together with 
their supervisors, before production can continue. The concept of Kaizen has been developed further and is now widely known as 'lean manufacturing' (Krafcik, 1988). Lean principles were implemented in production processes, for example by reducing distances between work stations or by installing required tools and machines close to where they were used. The question arises, how creative workflows can be optimized through spatial adjustments and what kind of infrastructure is required to facilitate creative processes. Innovation processes such as design thinking or lean startup (Brown, 2008; Müller and Thoring, 2012; Ries, 2011) suggest a frequent switching between process steps and iterations between teamwork, ideation, prototyping, testing, etc., and hence require different environments than traditional (office) workspaces. The shown spatial instantiations present a first step in this direction.

\section{DISCUSSION}

With this paper we presented selected instantiations of creative spaces from various institutions and linked them to a theoretical typology of creative spaces. This peek into the workspace design of innovation organizations might be of practical relevance for practitioners and spatial planners who want to develop creative spaces. The analysis of the found instantiations in the 18 visited institutions has multiple theoretical and practical implications. First, the cases represent corroborations of the creative space typology of Thoring et al. (2018a). Second, the concrete instantiations of different spatial qualities probe the solution possibilities of creative spaces in practice. Third, the examples are theoretically embedded into the contextual research literature. Consequently, these insights and new design possibilities can be used not just for inspiration but also for a theory-driven catalogue of design choices to guide practitioners and researchers within the vast possible solution space. However, we did not evaluate the actual impact of the spatial designs on creativity and innovation efforts in the analysed institutions, which could be achieved in future work, for example through follow-up interviews with the users. Another limitation of this study is its lack of completeness. Since we did not get access to the entire premises of each visited institution, we might have missed additional spatial features. We focused on occurrences of creative space instantiationsnot on possible absences. Nevertheless, the visits of the spaces followed a strict research protocol that could be repeated in other institutions, and the analysis of the instantiations showed a theoretical saturation.

\section{ACKNOWLEDGEMENTS}

We would like to thank the pictured institutions for providing insights into their work environments.

\section{REFERENCES}

Borges, S., Ehmann, S. and Klanten, R. (2013), Work scape. new spaces for new work. Gestalten, Berlin. Brown, T. (2008), "Design Thinking”. Harvard Business Review Vol. 86, pp. 84-92.

Bryant, M.E. (2012), Physical Environments Conducive to Creativity and Collaboration Within the Work Environment (Master Thesis).

Ceylan, C., Dul, J. and Aytac, S. (2008), “Can the office environment stimulate a manager's creativity?” Human Factors and Ergonomics in Manufacturing \& Service Industries Vol. 18, pp. 589-602.

Cross, N. (2001), "Designerly Ways of Knowing: Design Discipline Versus Design Science”. Design Issues Vol. 17, pp. 49-55.

Doorley, S. and Witthoft, S. (2012), Make space: how to set the stage for creative collaboration. John Wiley \& Sons, Hoboken, N.J.

Dudek, M. (2012), Spaces for young children: A practical guide to planning, designing and building the perfect space, 2nd Revised edition. ed. National Children's Bureau Enterprises Ltd, London.

Dul, J. and Ceylan, C. (2011), "Work environments for employee creativity”. Ergonomics Vol. 54, pp. 12-20.

Dul, J., Ceylan, C. and Jaspers, F. (2011), "Knowledge workers' creativity and the role of the physical work environment". Human Resource Management Vol. 50, pp. 715-734.

Ehmann, S., Borges, S. and Klanten, R. (2012), Learn for life: New architecture for new learning. Gestalten, Berlin.

Georgi, W. and McNamara, C. (2016), The other office 2: Creative workplace design. Frame Publishers, Amsterdam.

Grieco, L. and van Rossum-Willems, M. (2017), The Other Office 3: Creative Workspace Design, 01 ed. Frame Publishers, Amsterdam.

Groves-Knight, K. and Marlow, O. (2016), Spaces for innovation: The design and science of inspiring environments. Frame Publishers, Amsterdam.

Imai, M. (1986), Kaizen: The Key to Japan's Competitive Success, New edition. ed. Mcgraw Hill Book Co, New York.

Kangas, M. (2010), "Creative and playful learning: Learning through game co-creation and games in a playful learning environment". Thinking Skills and Creativity Vol. 5, pp. 1-15. 
Kato, I. and Smalley, A. (2012), Toyota Kaizen Methods : Six Steps to Improvement. Productivity Press.

Krafcik, J.F. (1988), “Triumph of the lean production system”. MIT Sloan Management Review Vol. 30, p. 41.

Kristensen, T. (2004), “The physical context of creativity”. Creativity and innovation management Vol. 13, pp. 89-96.

Lewis, M. and Moultrie, J. (2005), "The organizational innovation laboratory". Creativity and innovation management Vol. 14, pp. 73-83.

Lin, S.Y. (2009), Physical Workspace and Creative Performance. Sun Yat-Sen University.

Lindahl, G.A. (2004), "The innovative workplace: An analytical model focusing on the relationship between spatial and organisational issues". Facilities Vol. 22, pp. 253-258.

Magadley, W. and Birdi, K. (2009), "Innovation labs: an examination into the use of physical spaces to enhance organizational creativity". Creativity and innovation management Vol. 18, pp. 315-325.

Martens, Y. (2011), “Creative workplace: instrumental and symbolic support for creativity”. Facilities Vol. 29, pp. 63-79.

McCoy, J.M. and Evans, G.W. (2005), "Physical work environment”. Handbook of work stress pp. 219-245.

McCoy, J.M. and Evans, G.W. (2002), "The potential role of the physical environment in fostering creativity". Creativity Research Journal Vol. 14, pp. 409-426.

Miller, R., Casey, M. and Konchar, M. (2014), Change Your Space, Change Your Culture: How Engaging Workspaces Lead to Transformation and Growth, 1st ed. John Wiley \& Sons, New York.

Mirchandani, N. (2015), Future schools: Innovative design for existing and new build. Riba Enterprises, Newcastle upon Tyne.

Müller, R.M. and Thoring, K. (2012), "Design thinking vs. lean startup: A comparison of two user-driven innovation strategies", in: Leading Innovation through Design. pp. 91-106.

Oksanen, K. and Ståhle, P. (2013), "Physical environment as a source for innovation: investigating the attributes of innovative space". Journal of Knowledge Management Vol. 17, pp. 1-1.

Paoli, D.D. and Ropo, A. (2017), “Creative workspaces - a fad or making real impact?” Journal of Corp Real Estate Vol. 19, pp. 157-167.

Paoli, D.D., Sauer, E. and Ropo, A. (2017), “The spatial context of organizations: A critique of 'creative workspaces."” Journal of Management \& Organization pp. 1-22.

Peschl, M.F. and Fundneider, T. (2014), "Designing and Enabling Spaces for collaborative knowledge creation and innovation: From managing to enabling innovation as socio-epistemological technology". Computers in Human Behavior Vol. 37, pp. 346-359.

Polanyi, M. (1966), The tacit dimension. Doubleday, Garden City, N.Y.

Ries, E. (2011), The lean startup: how today's entrepreneurs use continuous innovation to create radically successful businesses. Crown Business, New York.

Sarkar, P. and Chakrabarti, A. (2008), "The effect of representation of triggers on design outcomes". Ai Edam Vol. 22, pp. 101-116.

Sassenberg, K., Moskowitz, G.B., Fetterman, A. and Kessler, T. (2017), "Priming creativity as a strategy to increase creative performance by facilitating the activation and use of remote associations". Journal of Experimental Social Psychology Vol. 68, pp. 128-138.

Snead, L. and Wycoff, J. (1999), "Stimulating innovation with collaboration rooms". Journal for Quality and Participation Vol. 22, pp. 55-57.

Stewart, M. (2004), The other office: Creative workplace design. Frame Publishers, Birkhäuser, Amsterdam ; Basel ; Boston.

Svihla, V. (2010), "Collaboration as a dimension of design innovation”. CoDesign Vol. 6, pp. 245-262.

Thoring, K., Desmet, P. and Badke-Schaub, P. (2018a), "Creative environments for design education and practice: A typology of creative spaces”. Design Studies Vol. 56, pp. 54-83.

Thoring, K., Gonçalves, M., Mueller, R.M., Badke-Schaub, P. and Desmet, P. (2017a), Inspiration Space: Towards a theory of creativity-supporting learning environments, Proceedings of the Design Management Academy Conference (DMA), Hong Kong, CN, pp. 1539-1561.

Thoring, K. and Mueller, R.M. (2014), Spatial Knowledge Management in Design Education, Proceedings of the Spring Cumulus Conference, Aveiro, Portugal, pp. 581-594.

Thoring, K., Mueller, R.M., Badke-Schaub, P. and Desmet, P. (2017b), A creative learning space development toolkit: empirical evaluation of a novel design method, Proceedings of the 21st International Conference on Engineering Design (ICED17), Vancouver, Canada, pp. 245-254.

Thoring, K., Mueller, R.M., Badke-Schaub, P. and Desmet, P. (2016), Design the Campus: Introducing a Toolkit for Developing Creative Learning Spaces, Proceedings of the Cumulus Conference, Nottingham, UK, pp. 358-368.

Thoring, K., Mueller, R.M., Luippold, C., Desmet, P. and Badke-Schaub, P. (2018b), "Co-creating an idea lab: lessons learned from a longitudinal case study". CERN IdeaSquare Journal of Experimental Innovation Vol. 2, pp. 30-37.

Waber, B., Magnolfi, J. and Lindsay, G. (2014), "Workspaces That Move People”. Harvard Business Review Vol. 92, pp. 68-77.

Yin, R.K. (2003), Case study research: design and methods. Sage Publications, Thousand Oaks, Calif. 